\title{
Ohio's Balanced Growth Program: a Case Study of Collaboration for Planning and Policy Design
}

Wendy A. Kellogg

Cleveland State University, w.kellogg@csuohio.edu

Follow this and additional works at: https://engagedscholarship.csuohio.edu/urban_facpub

Part of the Urban Studies and Planning Commons, and the Water Resource Management Commons How does access to this work benefit you? Let us know!

Publisher's Statement

(c) 2009 Taylor \& Francis (Routledge)

\section{Original Citation}

Kellogg, W. A. (2009). Ohio's Balanced Growth Program: a case study of collaboration for planning and policy design. Journal Of Environmental Planning \& Management, 52(4), 549-570.

\section{Repository Citation}

Kellogg, Wendy A., "Ohio's Balanced Growth Program: a Case Study of Collaboration for Planning and Policy Design" (2009). All Maxine Goodman Levin School of Urban Affairs Publications. 012373.

https://engagedscholarship.csuohio.edu/urban_facpub/73

This Article is brought to you for free and open access by the Maxine Goodman Levin School of Urban Affairs at EngagedScholarship@CSU. It has been accepted for inclusion in All Maxine Goodman Levin School of Urban Affairs Publications by an authorized administrator of EngagedScholarship@CSU. For more information, please contact library.es@csuohio.edu. 


\title{
OHIO'S BALANCED GROWTH PROGRAM: A CASE STUDY OF COLLABORATION FOR PLANNING AND POLICY DESIGN
}

\author{
Wendy A. Kellogg, Cleveland State University
}

\begin{abstract}
This paper describes the collaborative planning process for a new landscape planning programme in Ohio that seeks to influence land urbanisation patterns through joint local land use decision making on a watershed basis. The programme was developed through a collaborative process by a state agencyappointed task force that included agency staff and a wide range of stakeholders. The paper describes the process in terms of the collaborative mechanisms, the participants, the programmatic ontputs, and the social and organisational outcomes that set the foundation for enhanced watershed quality through better land use decision-making practices. Key collaborations formed during the process were inter-agency collaborations, a non-pronit organisation that partnered with the agencies, and that of state agencies with local governments to develop watershed-based land use plans. A most critical outcome was creation of a learning community, through an exploratory research process that used multiple methods of data gathering and consensus-building deliberation. The paper is based on a review of published documents and plans, meeting minutes, participant observation of committee and workgroup meetings and interactive research.
\end{abstract}

\section{Introduction}

This paper presents a case study of collaborative planning for a new 'smart growth' landscape planning programme in Ohio, USA. The programme was developed by a state-level commission charged with protecting the Ohio portion of Lake Erie and its tributary river systems. While local governments have been involved in watershed planning to address pollutants in the US (Clean Water Act 1972), the programme focused on local land use in a watershed-scale planning process, an approach uncommon in the US (Kaufman 2002). Despite being an exception, the approach was ultimately deemed both the most technically appropriate and the most feasible politically and institutionally in a state with a weak land planning culture and institutions. Given the policy and planning context, the design of the programme required a collaborative planning process across a range of institutions, governments and stakeholder groups from several levels of organisational hierarchy and

*Email: w.kellogg@csuohio.edu 


\section{OHIO'S BALANCED GROWTH PROGRAM}

geographic scales. The design of the programme was informed by an exploratory, interactive research process that used multiple methods of data gathering and consensusmbuilding deliberation.

The paper first describes the conceptual framework of collaborative environmental planning used to structure the case study. It then provides background on the institutional and organisational context for the Ohio Balanced Growth Program (BGP). The case describes the collaboration in this new programme in terms of the participants and the mechanisms through which collaboration was achieved, the planning objectives, and the outputs and outcomes of the process, which fostered an integration of planning and management function to solve complex socioeconomic/ ecological problems.

\section{Collaborative envirommental planning and management in watershed contexts}

Collaborative environmental planning and management (CEPM) is a process of "engaging citizens, along with government officials and interested stakeholders, in all phases of the policy process" (Koontz 2006, p. 15). This new 'governance" acknowledges the need to share responsibility with stakeholders outside the formal government in order to co-produce and achieve public goals (Newman et al. 2004). The origin or impetus for collaboration, and the resulting administrative goals for collaboration, can be legalistic, instrumental and political. Public agencies seek collaborative processes as a result of legislative mandate or executive order, which may assign shared responsibility for programme development (Kellogg et al. 2005). This 'consensus-rulemaking' (Booher 2004, p. 37) involves stakeholders in coproduction of the agency programme and its implementation mechanisms (Cooper and Kathi 2005). Instrumentally, agencies gain scientifically better programmes through collaboration, often driven by the need for knowledge and experience that rests outside an agency. Co-production of knowledge through joint-fact-finding can enhance mutual understanding of complex environmental problems (Ozawa 1991) as a fuller range of knowledge is incorporated. This can lead to improved efficacy as information and skills are shared (Innes and Booher 1999, Wiig 2002). A wider understanding can, in turn, be distributed through the network of collaborators (Heinz Center 2004, Coastal Resources Center 2004), building organisational capacity across disciplines and kinds of knowledge, both tacit and formal. Agencies can share implementation and management responsibilities within this broader network (Wondolleck and Yaffee 2000, Heikkila and Gerlak 2005). Finally, agencies may also build political legitimacy and support among constituents or reduce conflict through the involvement of external client groups, particularly where the problems to be addressed are highly contested (Harter 1982, Wondolleck and Yaffee $2000)$.

The trend toward collaborative resource management has strengthened in the last decades in the US, with many federal and state agencies working with stakeholders on watershed management and other landwater issues (Booher 2004, Koontz and Johnson 2004, Randolph 2004, Heikkila and Gerlak 2005, Koontz 2006). This approach has been used in Ohio by several state agencies for development of coastal management training programmes as well (Kellogg et al. 2005).

It can be argued that CEPM as an organising framework for planning has been informed by efforts to improve watershed planning, akin to what has been observed more generally: as the problems addressed by administrative agencies have grown 


\section{OHIO'S BALANCED GROWTH PROGRAM}

more complex, so have the organisational structures required to address them (Randolph 2004, Heikkila and Gerlak 2005). Decision making in a watershed context expands the scope of scientific information needed (water chemistry, aquatic biology, terrestrial runoff patterns, etc.) and the number of decision makers in many different settings (local and state government, private landowners, and other users). As Booher (2004) notes, traditional approaches under conditions of clear agency hierarchy and single resource mandates have shifted toward loosely configured collaborative arrangements addressing interdisciplinary problems, such as those inherent in watershed planning. State agencies now routinely engage other governments and interest-based stakeholders, working across local, state and federal jurisdictional responsibilities to forge ad hoc and ongoing relationships to address place-specific problems.

In theory, more collaborative processes may improve decision making in watershed and land use planning and management, and in the longer term, improve environmental or resource quality more effectively than less systemic approaches. Mandarano (2008) recently reviewed evaluations of collaborative processes that verify outcomes such as enhanced social and intellectual capital and more robust management systems. Whether or not collaborative structures and processes lead to improvement in envirommental or resource quality is more challenging, but evaluations have documented the change in environmental parameters such as restoration projects and land protection (Koontz and Thomas 2006). However, the overall resource response to policy or programme changes may take years. In addition, it is usually not possible to exclude influences of other programmes and behaviours on a given body of water that also might exert influence (GLC 2005 , Koontz and Thomas 2006). Nonetheless, programmes should include metrics for evaluating participation by relevant parties in implementation practices and any resource changes when feasible.

Conceptually, CEPM is characterised here in terms of the specific programmatic purpose/objective; the participants and the mechanisms through which their collaboration was carried out; the output from the collaboration (reports, policies, etc); and the outcomes of the collaboration (such as organisational networks, planning capacity, and integration of planning and management function to solve complex environmental/ecological problems) (see Figure 1).

\section{Landscape planning in Ohio: the context for CEPM}

While many states experiencing rapid population growth and land urbanisation adopted smart growth programmes during the 1990s (Nelson and Duncan 1995, Nelson 2002), states in the Great Lakes basin (Figure 2) have lost population overall while experiencing significant movement of urban populations to the metropolitan fringe. These states experience sprawl without growth (Pendall 2003). Landscapeoriented programmes, where they exist, emphasise retention of population in core settlements and the loss of small town or rural character at the metropolitan fringe.

The policy responses occur in relatively weak institutional setting for planning compared to other states in the US, and much weaker than in Canada, the UK or continental Europe. The relative strength of planning institutions and culture in a given location can be described in terms of the locus of land use authority, the requirements for planning imposed by higher levels of government, and the capacity for and practice of planning at local level. For example, planning function in both 


\section{OHIO'S BALANCED GROWTH PROGRAM}

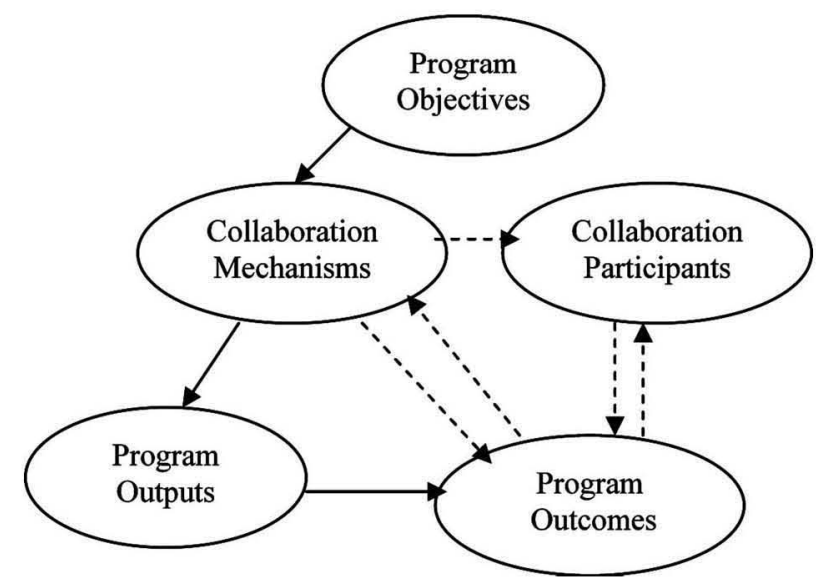

Figure 1. Conceptual model of CEPM.

Canada and the UK has traditionally been located centrally, in either national or provincial governments, with successively lower levels of government required to conform to land use requirements set from above (Cullingworth 1993). ${ }^{1}$

In the US, the role of federal government in land regulation is severely constrained both by a cultural tradition of localism and by constitution and law. States are the locus of legal authority in the confederation. However, only slightly more than half the states exert land use authority, although most have programmes focusing on environmentally sensitive land or resources (Nelson and Moore 1996, Breggin 2003). Land use authority is vested in local governments through charters of incorporation. Effective management of land urbanisation has been achieved in some states through a combination of strategies: state assertion of land use authority; a state-level planning agency which conducts land use planning at a state or regional scale; state requirements for comprehensive plans by local incorporated entities; requirements for vertical (with higher levels) and horizontal (with adjacent jurisdictions) consistency (Nelson and Moore 1996, Carruthers 2002, Carruthers and Ulfarsson 2002, Richardson et al. 2003, Bengston et al. 2004). No state in the Great Lakes basin meets all or even most of these criteria and all states grant land use authority to local (municipal or township) governments. The case here is in Ohio, which shares the 'home rule' culture found across the Great Lakes basin, whereby unincorporated townships (roughly $60 \mathrm{sq}$. $\mathrm{km}$ each) as political entities also have some land use authority and other police powers. There is no land planning function at the state level, no vertical or horizontal consistency requirements, and few requirements for planning at the local level (Meck and Perlman 2002). Counties (an administrative level enfolding townships and incorporated areas) do not have de jure land use authority, resulting in a highly fragmented decision-making context, which in turn has made regionalised land use decisions relatively rare. Indeed, there is often an anti-planning bias at the local level, particularly if increased regulation of private property or the loss of 'home rule' authority is proposed.

In this context the Ohio Lake Erie Commission (OLEC), charged with protection of Lake Erie and its tributary watersheds, developed an administrative planning process to influence land development patterns and practices. The Ohio Lake Erie Commission consists of the directors of six state executive branch agencies and 


\section{OHIO'S BALANCED GROWTH PROGRAM}

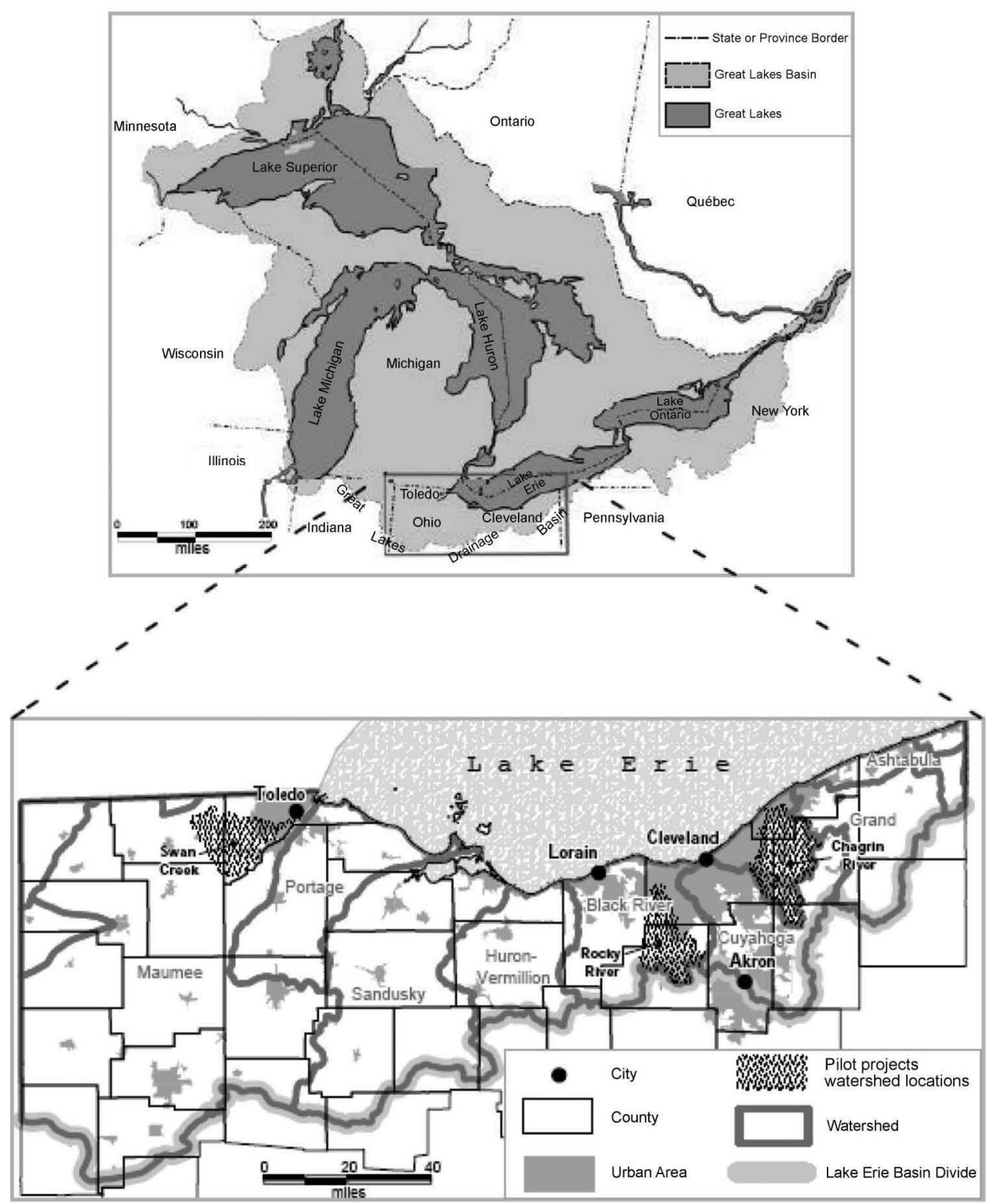

Figure 2. The Great Lakes States and Provinces, Ohio's Lake Erie basin, and Balanced Growth pilot watershed locations.

departments (natural resources, transportation, environmental protection, development, agriculture and health), who advise the governor on natural resources, water quality and economic development related to Lake Erie (OLEC 2005). The Lake Erie basin covers approximately one-quarter of the state's territory, and includes two of the state's largest urbanised areas (Cleveland and Toledo). While the agencies operate across the entire state of Ohio, their participation in OLEC, and in the Balanced Growth Program itself, only applies to the Lake Erie Basin portion of the state. Together these agencies control several billions of dollars annually through 


\section{OHIO'S BALANCED GROWTH PROGRAM}

public spending on infrastructure, economic investment, regulation, conservation and other public programmes. OLEC has a staff of three whose role is to co-ordinate with other state agencies and departments, other units of government, state legislators and the public and support the commissioners (the agency directors) as they develop policies. The Lake Erie Protection and Restoration Plan (LEPRP) of 2000 (OLEC 2000 ) was developed by OLEC staff and its member agencies in response to growing concerns with water pollution, habitat degradation and low density land urbanisation in the Ohio Lake Erie basin (OLEC 2000). The objectives and strategies of the plan are guided by 10 principles for a sustainable Lake Erie watershed. Most relevant for issues related to landscape considerations are its first two principles: (1) maximise investment in existing core urban areas, transportation and infrastructure networks to enhance the economic viability of existing communities; and (2) minimise the conversion of green space and loss of critical habitat areas, farmland, forest and open spaces to urbanised uses. Thus the plan makes an explicit emphasis on the location of new development and land use change (OLEC 2000, p. 8). However, the state agencies in OLEC adopting the plan have no legal authority for land use decision making, which rests at the township, village, and city level in Ohio.

\section{Methodology}

Information which forms the basis for this review of the Ohio Balanced Growth process was gathered through several methods. In part, the information is the result of an interactive research process that formed the basis of the collaboration among participants. In this setting, research (and its reporting) is considered a social action in which participants jointly create social meaning based on the co-production of knowledge. Rather than subject-object, the relationships are subject-subject, with shared social knowledge developed over time through ongoing dialogue and relationship-building (Astleithner and Hamedinger 2003). The author served as a member of the task force appointed by the Ohio Lake Erie Commission that developed the Balanced Growth Program. One year into the process, the author was appointed to chair one of the three workgroups of the task force, in particular, the workgroup that focused on development of a watershed/regional planning framework for the programme. In those roles, the author participated in approximately 10 task force meetings and organised (with the executive director) and ran planning workgroup meetings on a monthly basis from early February 2002 until the fall of 2003. She also attended (as an observer) various meetings of the two other work groups, and meetings of the steering committee that had been appointed to assist the task force. She also observed a set of public meetings organised by the Ohio Lake Erie Commission, and the meetings of the Commission itself when the Balanced Growth Program was discussed and adopted. She co-chaired and ran meetings and workgroup meetings for the Indicator Steering Committee project as well (described below). Participant observation of other committee, workgroup and agency meetings was conducted between 2001 and 2006 to collect data regarding committee deliberations and decision-making processes.

A review of published documents and plans from the state agencies identified consensus embodied in plans and policies. Minutes from the task force and workgroup meetings were kept and published by the OLEC staff supporting the process. A review of meeting minutes of the planning workgroup identified the deliberative topies and progress in developing the planning framework. Notes 


\section{OHIO'S BALANCED GROWTH PROGRAM}

generated during the meetings and after the meeting (by this author) were also used to verify the key issues regarding political and technical feasibility that arose during the process. The agendas for these meetings were set through a collaborative process between the author (as workgroup chair), the director of the OLEC staff, the chair of the task force and the chairs of the two other workgroups. The review of documents identifies the collaboratively-generated reality that emerged from the process, which exists 'outside' the observations of a single participant. Results from a separate, subsequent review of smart growth policies and their implementation (Kellogg 2007) placed the process described in this paper in a context of broader policy and planning trends well documented in the literature.

\section{Results: collaborative environmental planning and management for the Ohio Balanced Growth Program}

OLEC's administrative objectives for the Balanced Growth Program focused on development of policies and mechanisms through which the state could influence land urbanisation patterns. Figure 3 presents a schematic of the organisation of the Balanced Growth Program.

\subsection{Collaboration mechanisms and participants}

Several collaboration mechanisms formed the heart of the programme development and implementation process, including the Blue Ribbon Task Force, three workgroups of the task force, an Indicators Steering Committee, and a regional non-profit organisation that funded subsequent research. These are discussed below.

\subsubsection{Blue Ribbon Task Force}

The Lake Erie Restoration and Protection Plan called for creation of a "Balanced Growth Blue Ribbon Task Force... charged with advising the Lake Erie

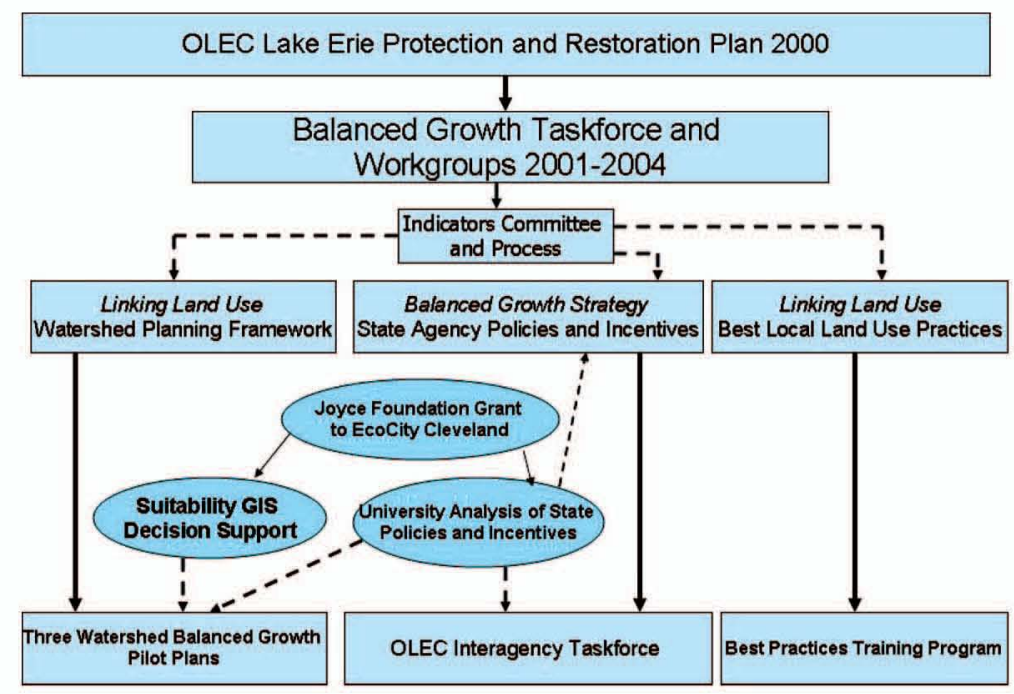

Figure 3. Organisation of the Ohio Balanced Growth Initiative/Program. 


\section{OHIO'S BALANCED GROWTH PROGRAM}

Commission on strategies that will balance the protection of the Lake Erie watershed with continued economic growth" (OLEC 2000, p. 10). This task force was appointed by the commission in 2001, and it first met in the November 2001, meeting every three months over the anticipated one year or so of the process. ${ }^{2}$ The initial tenor of the meetings was tense, with many members sceptical of the state's commitment to landscape change. Several members of the task force and the research staff working with the commission were well aware of smart growth as an organising framework for addressing sprawl in other states and raised the question as to why the LEPRP had used the term 'balanced growth' instead. The chair of OLEC (who at the time was the director of the state's natural resources agency) noted while the names sustainable development or smart growth had been used in other places, "we will continue to expand our economy and will inevitably experience continued development and population growth. But, Balanced Growth also is a belief that growth can occur in ways that will minimally impact the health of the ecosystem" (OLEC 2000, p. 25). At the first task force meeting participants also asked "What does 'balanced' and what does 'growth' mean?" Much discussion ensued, and there really was no consensus at that point. However, by the end of the process some two years later, the notion of balance had been changed. By the time the BGP was rolled out for public comment prior to its adoption by OLEC, balanced growth was defined as "a strategy to protect and restore Lake Erie and its watersheds to assure that long-term growth equally benefits competitiveness, ecological health and quality of life". This language evolved after the group deliberated and reached consensus that longuterm economic health and quality of life is dependant upon long term ecological health in the basin. A compromise, but well beyond the initial notion to have growth and mitigate environmental damages.

The role of the task force was to generate the elements of the programme and recommend implementation mechanisms. This proved to be a second area of tension, as the agency chair of OLEC explained that they sought a programme that could be implemented through the executive office without new legislation, and because of the state's fiscal constraints, that no new money would be allocated for implementation. The response to his comments from the members was one of disbelief, with members asking what would be possible at all with these constraints (BG Task Force Minutes 2001). However, as the task force worked over several years with OLEC staff and leadership, it became more apparent that the caveat against legislation was intended to avoid delay of the programme's implementation if it became engaged in legislative debate (which was likely given the legislature's conservative antagonism to planning in general). Development of the Balanced Growth Program was a high priority for OLEC, and the organisation looked to the task force members to support its effort to move the process forward.

Task force members represented a wide cross-section of stakeholders, including: state agencies; the private sector (property rights, homebuilders and chamber of commerce associations); county planning commissions; environmental and watershed nongovernmental organisations (NGOs); township, municipal and county commissioner associations; Metropolitan Planning Organisations (MPOs); and academics from biology, urban studies and law. A civil engineer in private practice in the Lake Erie basin was elected chair of the task force. This diverse membership helped ensure that whatever was proposed would be scientifically grounded, tested against a wide set of perspectives, and thus more administratively and politically feasible. 


\section{OHIO'S BALANCED GROWTH PROGRAM}

A critically important participant in the process was EcoCity Cleveland, a nonprofit environmental planning organisation. EcoCity Cleveland was founded in the early 1990 s by a journalist who had reported on environmental issues in northeast Ohio. For 10 years the organisation had conducted applied research and published studies of the major land use and environmental trends in the region and their impact on natural resources and quality of life. The staff provided research on existing smart growth programmes in the Great Lakes basin and the United States, recorded task force and workgroup meetings, and generated reports for the process (EcoCity Cleveland 2006). The information from other state programmes focused on programmes in Maryland, Pennsylvania, Wisconsin and Washington. The information assembled included: the goals of the programme; metrics used to measure implementation progress; requirements for local and regional planning; any state-level plans (land use plan, conservation, transportation) that would support the programme; the assistance provided by the state to local governments for planning (data, financial, decision support); the locus of authority (legislation, executive) in state government, implementation strategies; the role of NGOs and other stakeholders; any overall landscape changes that were desired; and any outcomes to date.

Without this work and the information generated, the workgroups would have started from scratch. Knowledge of the design of other state programmes accelerated the process, helping to overcome the time delays caused by the change in leadership. The research reports allowed members to form a shared knowledge base more quickly and served as a single text from which changes could be negotiated and a programme design for Ohio crafted.

A second benefit from EcoCity's participation was to add an immediate legitimacy to the Balanced Growth Program in the regional environmental community, which had strong scepticism about the state's intentions. NGOs have played an important part in the other states as well, although in the other states the ' 1000 Friends of organisations played an advocacy, rather than research, role. ${ }^{3} \mathrm{~A}$ third benefit was EcoCity's national stature as an environmental organisation, due in part to publication of its newsletter, which had won an Utne Reader award. ${ }^{4}$ Finally, EcoCity's participation helped move the BGP into the implementation stage. EcoCity received a grant from the Joyce Foundation that funded two additional studies. One supported development of a basic GIS decision-making framework for the watershed pilot plan development. The second supported a review of academic and policy literature on state operations and programmes across the US for their influence on landscape change, which assisted OLEC in developing implementation mechanisms (see Figure 3).

\subsubsection{The three workgroups: state policies and operations, regional planning, and} local land use and zoning practices

The task force eventually divided into three work groups: state agency operations, regional planning, and local land use and zoning practices. Each workgroup consisted of members of the task force phus additional stakeholders identified as critical in terms of expertise or for building constituent support. The workgroups met over a two-year period to work on their assigned areas of programmatic development. The workgroups developed recommendations that led to important outputs of the BGP (see below). The focus here is on the work of the regional planning workgroup and its support. 


\section{OHIO'S BALANCED GROWTH PROGRAM}

The 'planning and incentives workgroup', as it came to be known, consisted of approximately a dozen members of the larger Balanced Growth Task Force. The charge to the planning workgroup was to "recommend state actions and incentives that will promote the development and implementation of regional plans" (Planning and Incentives Workgroup Meeting Agenda 2002), a recognition by OLEC that local jurisdictions could not individually address water resource issues. The members represented three OLEC agencies (development, environmental protection and transportation), county planning commissions, regional councils of government, land development interests, the state-wide municipal league, a regional chamber of commerce group, an environmental advocacy organisation, and an academician (this author). Members beld expertise across a wide variety of scientific and technical fields (biology, engineering, economics, government management and administration, business administration and environmental planning) and approached the work from within their disciplinary and organisational perspectives. The workgroup met for over two years, with work sessions scheduled from two to four months apart depending on the stage of the process. ${ }^{5}$ The knowledge-base that informed development of the planning framework was the result of an inductive, iterative, interactive participatory research process as described by Astleithner and Hamedinger (2003), in which stakeholders became partners in identifying divergent forms of knowledge (tacit and formal) that would be critical to the design and implementation of this new planning framework. The workgroup first reviewed the data collected by the EcoCity Cleveland staff on existing smart growth programmes from across the US. Workgroup members then shared knowledge formally (through a series of peer presentations about regional planning and the experience of each organisation) and informally (through discussion) about political feasibility, regional planning, current watershed activities across the state, the relationship of landscape to water quality, and a range of planning and implementation mechanisms to consider. This 'interactive decision making' (Edelbos and Klijn 2005) or collaborative learning process (Cooper and Kathi 2005) led to comproduction of the agency programme and its implementation mechanisms. It was this shared knowledge base regarding landscape change that allowed the group to reach a consensus as to what types of administrative and planning mechanisms would constitute a 'balanced growth' approach.

The overall objective of the workgroup was to identify the most likely 'ecologically effective' landscape planning framework and 'politically and institur tionally feasible' implementation mechanisms that would work in Ohio to protect tributary streams and rivers, riparian and coastal habitat and Lake Erie. The initial research and subsequent discussion and a review of the workgroup's charge led to identification of a set of research questions. The workgroup designed the planning framework by co-producing a response to the following questions:

- What planning unit or territory was the most appropriate in terms of scale, scientific basis, and political acceptability?

- How should the planning process be organised? By what kind of entity?

- What landscape pattern might be ideal or best suited to protect tributary rivers and streams?

- By whom and how should the plan be implemented? Using what policies and mechanisms? 


\section{OHIO'S BALANCED GROWTH PROGRAM}

The workgroup struggled over several months deliberating what would be the most appropriate planning unit or territory for the Balanced Growth Program. The concerns focused on the logical scale, the logical scientific basis and what would be politically acceptable. The group considered whether counties, service areas of existing metropolitan planning organisations (MPOs), regions defined on the basis of census population, or the regional commute 'shed' would be the appropriate regional scale for the BGP. Other members countered that since the purpose of the BGP was restoration of the Lake Erie watershed, the best fit scientifically was to work on a watershed basis. Some members doubted that a watershed framework was practical given that the boundaries of local governments are not organised on this basis. However, others suggested that many watershed-based planning and management efforts existed in the Lake Erie basin within OLEC's natural resources and environmental protection agencies and many watershed-oriented NGOs had worked to develop watershed management plans (Ohio State Watershed Network 2007), indicating a growing political acceptance of watershed-based approaches (Planning and Incentives Workgroup 2003a). Ultimately, the group came to a consensus to use watersheds as the planning unit based on the knowledge that had been collaboratively created.

The workgroup also spent considerable time identifying who should lead the watershed-based planning process. After much deliberation, the best configuration was deemed to be a partnership that must include local governments. Through discussion of the regional watershed approach and review of other state programmes, the workgroup determined that the focus of the Balanced Growth Program was the location (rather than timing) of land development to maximise investment in existing core urban areas and minimise the conversion of rural landscapes to urbanised uses.

\subsubsection{Indicator steering committee / Great Lakes Commission}

In 2005, the Great Lakes Commission offered to conduct the second of its 'Land Use Roundtables' in Ohio (the first was held in Michigan in 2004). OLEC staff suggested that the most useful focus for the roundtable would be to develop a set of indicators for the Balanced Growth Program that would serve to monitor the affect of the programme over time (personal communication, OLEC Director April, 2004). A steering committee and nearly 30 experts across a range of scientific and technical disciplines worked for a year on the indicators (GLC 2005). However, broader participation in the BGP was achieved through this process. $A$ set of smaller workgroups reached out to experts in natural resources, aquatic biology and chemistry, county and local planning agencies, and GIS, seeking their tacit and formal knowledge to develop and verify the relevance and practicality of a set of indicators. After working through these smaller groups, the steering committee and many of the other participants convened at Cleveland State University in January of 2005 to finalise the indicators. This was done through a one-day meeting of each of the workgroups, followed by use of an electronic voting system where all participants could rate the proposed set of indicators on the basis of scientific relevance, data availability and implementation feasibility. The process entailed hundreds of donated hours by participants, and was also supported by CSU, the Great Lakes Commission, and the US Environmental Protection Agency (GLC 2005). 


\section{OHIO'S BALANCED GROWTH PROGRAM}

\subsection{Outputs}

The set of recommendations delivered to the commissioners consisted of a planning framework for participation by local governments and stakeholders in regional watershed plans, a state incentives strategy to support the watershed plans, and a set of indicators for measuring progress in programme implementation. ${ }^{7}$

\subsubsection{The watershed land planning framework}

Published as Linking Land Use to Lake Erie, this framework is unique to Ohio and to the Great Lakes basin. Many watershed management plans have been developed in the Lake Erie basin containing recommendations for land use decisions supportive to watershed health. However, the role of local governments has not been central to the extent needed, challenging the overall feasibility of successful implementation of the plan. That is why the BGP approach is quite significant. The prerequisites for gaining access to funding for planning and implementation and other incentives through the programme stipulate that the watershed partnership that develops the plan must include at least $75 \%$ of the local government jurisdictions in the watershed, cover at least $75 \%$ of the watershed territory, and encompass at least $75 \%$ of the watershed population. To verify commitment, local governments were asked to supply a formal ordinance or resolution by the elected legislative body. This level was set to ensure a more representative plan, a plan that would be accepted by local governments (Planning and Incentives Workgroup 2003b).

The planning framework is conceptually a gravity model: 'pulling' development into existing areas, and 'pushing' development away from high priority resource areas (Pendall et al. 2002). The framework entails designation of priority development areas (PDAs) and priority conservation areas (PCAs). PDAs, which might be areas such as existing urban areas, industrial parks, special development districts and areas with infrastructure, would focus state investment in existing communities. The emphasis is on areas that were already served by services, or that would be needed in the short term by the community. PCAs, which might include parks, forest, wildlife areas, critical habitat, riparian areas and other environmentally sensitive areas, would focus state conservation funding to land of high riparian system value and help maintain interstices between settlement nodes.

Through the watershed planning process organised in the Balanced Growth Program, local communities would bring forward their proposals for PDAs and PCAs in their jurisdictions. Any conflicts in these proposals would be rectifed and resolved through this collaborative planning process. Once designated, both types of areas would guide the state government in its investments and direct incentives the state would provide to local governments and land developers. The areas would not be regulatory, and local governments will remain free to authorise land development or conservation according to their own plans. However, the level of influence by the state could be significant. Subsequent research for the programme (Kellogg 2007) estimates that the agencies of OLEC transfer several billion dollars to local governments each year through loans and grants for highway and road construction and maintenance, water and sewer infrastructure, open space and farmland conservation, and other 


\section{OHIO'S BALANCED GROWTH PROGRAM}

landscape-influencing programmes. Redirection of these funds into locally. designated priority areas could, over time, restructure the landscape in these watersheds. It is also anticipated that once a Watershed Balanced Growth Plan is approved, the local governments in the watershed would update their own comprehensive and economic development plans and direct their capital expenditures to implement the plan. Figure 4 presents a conceptual diagram developed during the workgroup process to illustrate the relationship of the state and local entities and their influence on the landscape.

\subsubsection{The state policies strategy document and programme incentives}

A second output of the process was the Lake Erie Balanced Growth Strategy, which was adopted by the commission in June 2006. This document outlined the administrative support to the pilot watershed projects, focusing on an incentives package gleaned from existing state administrative and funding programmes to influence both local jurisdictions and the private development market. The incentives were identified through an inventory of appropriate state programmes, the creation of a special state work group to provide additional technical assistance to communities in the pilot watershed processes, and improvements to state programmes in wetlands permitting, programme consistency and other state regulations (OLEC 2006b). Additional research on the state polices and incentives to support the pilot projects were also funded by EcoCity Cleveland. In addition to a review of relevant policy and academic literature, focus groups comprised of private sector real estate developers were convened. These groups were asked to identify which factors (availability of roads, utilities, financing, permits, etc.) tended to shape their development decisions. Results of this research were used to inform ongoing work of the OLEC interagency task force and a technical advisory committee comprised of other state agency staff and several former members of the original Balanced Growth Task Force from a variety of stakeholder groups (OLEC 2006b, Kellogg 2007).

\subsubsection{The indicators and monitoring plan}

A third programmatic output of the Balanced Growth Program development was a set of indicators and a monitoring plan to evaluate the effectiveness of the programme. It is not likely that an evaluation scheme can separate the positive effects of the watershed planning framework from other positive ecological changes associated with de-industrialisation, clean up of contaminated sites, abandonment of marginal farms reducing input of pollutants, reforestation efforts and other programmes directed at the land-water interface. However, an evaluation framework has been developed through which the state hopes to shed light on the affect of the Balanced Growth Program.

The indicator steering committee (described above) developed indicators of threetypes. The type one indicators focus on progress in programme adoption (as measured by participation in future BGP watershed planning, changes to local zoning, ete.). Type two indicators focus on changes in the landscape occurring as a result of implementation of the PDAs and PCAs (as measured by differences in population densities, infrastructure development, etc.) Type three indicators measure changes in the resource base itself (as measured by changes in riparian and aquatic ecological 


\section{OHIO'S BALANCED GROWTH PROGRAM}

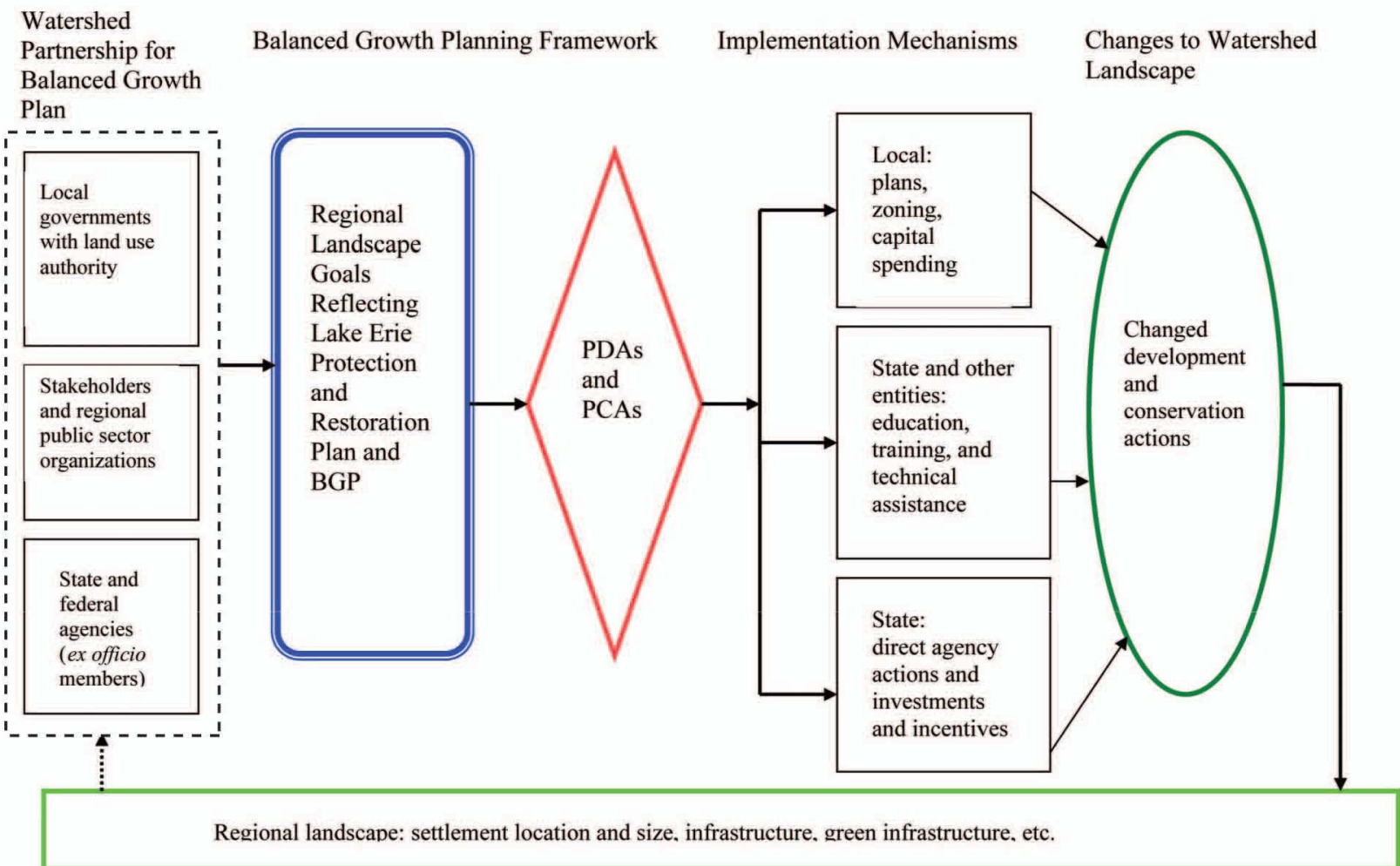

Figure 4. Balanced growth planning and implementation framework. 


\section{OHIO'S BALANCED GROWTH PROGRAM}

conditions (GLC 2005) (see Figure 5). OLEC agencies and other partners identified the status of databases and data collection for the biological and chemical indicators, ranking them according to the feasibility for implementation. Programmatic indicator data would be collected as pilot projects were started and finished and changes to local ordinances or practices were included in the watershed's Balanced Growth Plan and incentive funding awarded. The state has an extensive water quality and biological resource data collection system and was confident that most of the biological/resource indicators could be implemented with relative ease. However, several of the land use and socio-economic indicators, which would measure changes to the landscape resulting from implementation, were not readily implementable. The state commissioned additional research to identify the particular methodology and data that would be needed to assess socio-economic changes resulting from designation of PDAs and PCAs. This research was completed in mid-2008 (Lee and Kellogg 2009).

\subsection{Outcomes (and remaining challenges)}

'Outcomes' refers to the resulting changes in organisational and institutional capacity and intellectual capital, including stakeholder knowledge enhancement (Ozawa 1991, Innes and Booher 1999), leading to enhanced capacity of the agency and stakeholders to engage in collaborative implementation of the Balanced Growth Program (the environmental or resource outcomes will be evaluated in the future through the indicator programme). The Balanced Growth Program has laid the foundation for an enhanced capacity in the state for influencing land use decision making. It has stimulated local collaboration in a regional land use planning effort and created a learning network of stakeholders and organisations with an enhanced knowledge base as to what is scientifically appropriate and politically feasible for programme implementation.

\subsubsection{Initiation of local collaboration in regional land use planning}

There is no requirement in Ohio that local governments even notify adjacent jurisdictions of plans to encourage land development or conservation. The pilot

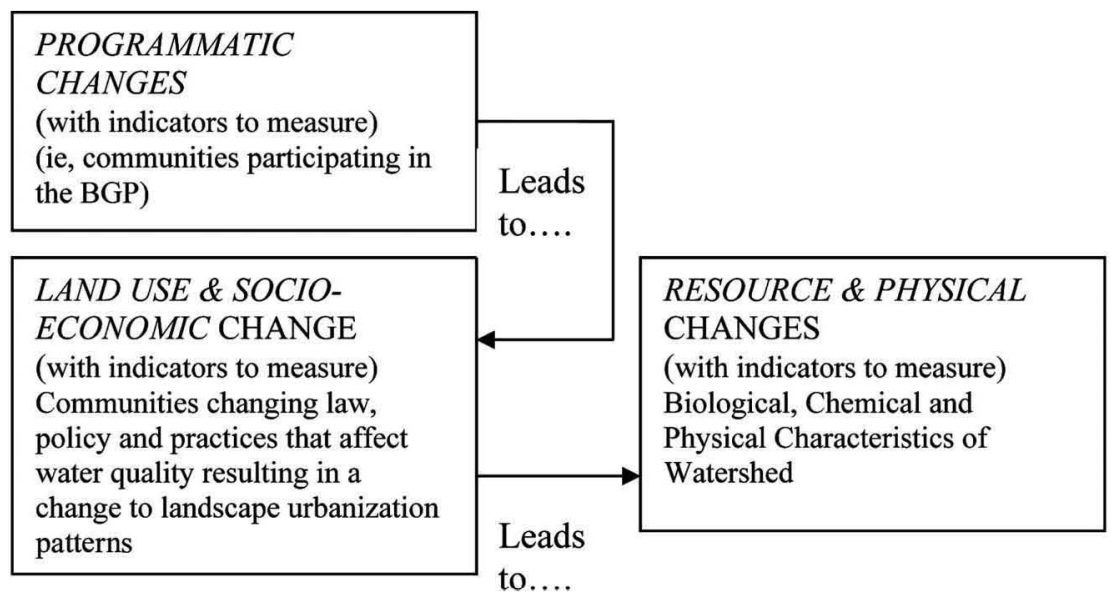

Figure 5. Three types of Balanced Growth indicators and expected change. 


\section{OHIO'S BALANCED GROWTH PROGRAM}

projects whereby local governments are collaborating on land use decisions to designated PDAs and PCAs has not been attempted in Ohio prior to the Balanced Growth Program. While the working group formulated how a watershed approach to land use decision making might work, attempting to anticipate all the policy and procedural challenges, in the end the group suggested a set of pilot planning projects to designate PDAs and PCAs and test the framework. These pilot projects have been supported in several ways by OLEC. OLEC secured US $\$ 600,000$ from the Ohio Water Development Authority for three, two-year pilot projects and released a call for proposals in spring 2005. Eight watershed organisations and government agencies from around the basin submitted applications. Awards were made on the basis of criteria designated by the workgroup and OLEC, including the organisational capacity of the organisation, confirmed participation by local jurisdictions in the watershed, applicability to different watersheds, and how well the proposed goals for the pilot project would help to implement the Lake Erie Protection and Restoration Plan. These criteria were used to bolster the likely successful completion of the plans, which would require considerable dialogue among the local jurisdictions. The awards were also given to achieve a geographic distribution across the basin and a variety of scales and types of watersheds (second vs. third order and predominantly rural vs. urbanised), in part to engender a sense of fairness among possible recipients of programme benefits, as suggested by Ashforth (1992). (See Figure 2 for the location of the pilot programmes). The three pilot projects began in January 2006 , with each planning process to take two years (OLEC 2006a). These are the first efforts in Ohio to engage multiple local governments in land use decision making. Completion of the pilot programmes is anticipated in early 2009, and a formal evaluation of their results is planned.

A key principle of the BGP was that the PDAs and PCAs would be designated by the Watershed Balanced Growth Partnerships consisting of local governments and key watershed stakeholders, not by state agencies. While some communities and states in the US have instituted the use of green belts or open space to constrain land urbanisation (Correl et al. 1978, Abbott 2002), most have been through regulatory mechanisms such as mandated community planning and consistency with state-level growth management programmes. The Ohio framework does not preclude development outside priority areas by local governments or the private sector, but development inside the PDAs and PCAs will have higher priority access to state financing programs and expedited permit review processes. This approach is similar to priority funding areas in Maryland (Cohen 2002) and Pennsylvania (Department of Economic Development 2005), but these are not locally designated, nor are these programmes implemented on a watershed basis. In this latter regard, Ohio's programme is unique in the US. Implementation of the Ohio programme will provide key lessons for other regionally-based planning efforts in terms of whether this incentive-based approach results in landscape-level change.

However, a series of challenges exist. Why should local governments participate in the programme at all? The programmatic response is to get access to funding incentives and a greater level of technical and administrative consideration. The design of the BGP stipulates that once local jurisdictions have designated PDAs and PCAs on a collaborative watershed basis, the state agencies in OLEC will prioritise ongoing loans and grants through their many different programmes to projects in these areas and to entities that participate in the Balanced Growth Plan in the watershed. However, the highly fragmented land use authority resulting from the 


\section{OHIO'S BALANCED GROWTH PROGRAM}

high number of jurisdictions and their relatively small size in the pilot watershed areas does not bode well for a regionalised approach, and future evaluations will assess whether the incentives provided by the state were sufficient to overcome this fragmentation.

Will local jurisdictions change their land use policies to comply? Long-term watershed thinking that overrides the tendency among each small jurisdiction to make decisions unilaterally must be encouraged for the programme to succed. The Balanced Growth Program implementation includes a multi-year series of workshops on land management practices focused on local decision makers and stakeholders. This educational outreach is intended to illustrate the benefits of watershed-based decision making and to bring information about the best practices and model zoning ordinances developed by the Balanced Growth Task Force. The state is also offering direct technical assistance to a small number of communities in the pilot planning areas to assist them in developing specific land management practices and adoption of some of the model land management and zoning ordinances that were developed as part of the original programme. However, these elements fall short of the more comprehensive decision-support systems that other states such as Pennsylvania, Michigan and Wisconsin have created to assist local governments.

A key question is whether the educational outreach by the BGP, together with other educational programmes focused on land use and water resources, will sway decision makers who must also contend with issues of tax revenue, schools, public safety and provision of services, which at times might contravene, or be perceived to contravene, collaborative land use decision making that would serve the Balanced Growth Program.

\subsubsection{Learning network and enhanced knowledge base}

The collaboration across multiple sectors began to develop a learning network cognisant of the scientific and political realities that not only shaped the programme, but might help to implement the programme in the future. Through the deliberative process to design the Balanced Growth Program, stakeholders and agency staff together became more aware of the scientific, technical and economic information that each organisation collected, and the knowledge embodied in their agency mandates and organisational missions. This knowledge was critical as the basis of sound decision making in terms of both the watershed as planning unit and the most feasible administrative structure for the Balanced Growth Program.

For example, the explicit connection to Lake Erie Protection and Restoration Plan provided a very strong logic for adopting the watershed-based land use planning framework. The planning unit has to reflect the resource itself, and the workgroup was convinced that the watershed unit was the most relevant and that many of the agencies had necessary data and experience to measure the affect of the programme. However, political feasibility was also important. Political culture in Ohio is conservative (meaning an aversion to government interference with property rights). In this context, an incentive based, voluntary approach for the BGP, rather than a regulatory approach, was the most feasible. When the planning workgroup deliberated there was considerable support for a more regulatory approach, which would have placed the BGP more in alignment with more typical growth management and smart growth programmes in the US. For example, the smart 


\section{OHIO'S BALANCED GROWTH PROGRAM}

growth programmes in Washington and Wisconsin require local and regional planning based on goals and model content identified in the state programmes. The Ohio programme did not adopt this approach, although the need to encourage local comprehensive planning was the topic of much discussion. Explicit focus on comprehensive planning was rejected as a requirement, in part because the state does not require this of municipal governments. A voluntary, incentive based approach was deemed more appropriate given the state's relatively low capacity regarding policies (land use planning) and the complex policy system (watersheds with multiple stakeholders and multiple jurisdictions sharing one ecosystem territory, the watershed) (as per Blair 2001) that exists in a state where many local governments eschew planning. However, it is hoped that involvement by local jurisdictions in the watershed-based land use planning process will encourage not only new knowledge about watersheds and their function, but also an appreciation of the benefits of planning itself. If this outcome of collaboration (an increase in social capital) is realised, it should result in changes to local comprehensive plans where these exist, and development of plans in communities currently without them. This outcome will be evaluated in the future to determine whether the incentive-only approach is effective.

Second, OLEC needed the cooperation across jurisdictions and organisations to provide funding support and continued input of critical information. For example, the role of EcoCity Cleveland as a non-profit education and planning support organisation in the process provided far more information for committee members than could have been brought to the decision making otherwise. In particular, the information about the smart growth programmes and experiences from other states allowed the workgroup to develop a more realistic framework. The unique partnership continued through the pilot project implementation, and EcoCity funded further research that reviewed state policies and programmes and helped to develop a GIS data platform for subsequent suitability analysis for the pilot watershed plans. This role for an NGO could be replicated in other smart growth programmes if these organisations have the capacity to mobilise additional resources. This capacity was particularly critical to support the effort in Ohio, a state that has been under significant fiscal constraints as the manufacturing economy in the Great Lakes 'rust belt' basin declines as population migrates to the 'sunbelt' states.

Finally, the task force and workgroups recommended that OLEC should create a technical advisory committee to maintain the connections between stakeholders with differing knowledge sets needed for a more collaborative implementation and management framework. This group was created and although the technical advisory committee meets infrequently, its individual members are consulted regularly for their guidance on the implementation process. The committee members continue to provide oversight and advice to OLEC as it implements the pilot projects and the other aspects of the BGP.

The original plan also stipulated creation of an interagency task force to review the programmes of each agency to determine how they can best support implementation of the BGP. The design of the BGP stipulates that the OLEC agencies will not contravene the wishes of the local governments embodied in the PDAs and PCAs in their own investments (roads, permits, other spending) and related policies. This second aspect of the state's role may prove challenging. Each agency has authorising legislation that imposes a set of administrative mandates. Each agency has administrative programmes that have been developed over decades, 


\section{OHIO'S BALANCED GROWTH PROGRAM}

and changing institutional and organisational culture to new ways of making decisions can be very, very difficult (Agócs 1997, Val and Fuentes 2003). Agencies have longwstanding external client and intermorganisational relationships, which may mitigate against internal change as well (Pfeffer and Salancik 2003). The state agencies in OLEC have agreed to comply with locally-designated PDAs and PCAs in their own plans and programmes (OLEC 2004), but the challenge is whether their continued collaboration in the programme will in fact reshape the ongoing operations and priorities of the agencies.

\section{Conclusion}

This case study illustrates that a collaborative, planning process can balance apparent conflicts between scientific appropriateness and political feasibility. The conflicting ideologies or interests of the participants were valuable input in the process to create a programme that might actually bring landscape-level land use decision making to Ohio. The mix of participants and the mechanisms for their collaboration arguably produced better results than what would have been achieved in a less inclusive process, much as has been documented in other collaborative consensus-building processes (Innes and Booher 1999). The overall effectiveness of the Balanced Growth Program will rely, as did its generation, on collaborative implementation participation across a broad range of stakeholders, including state agencies, regionally-organised planning bodies, local government decision makers and citizens. Thus far, necessary steps for success have been put in place, including state-level strategies and policies, funding for watershed planning activities, organisation of watershed entities and educational outreach. Many of the initial participants have maintained their relationship with the programme as it is being implemented and have provided ongoing technical assistance and research. A collaborative learning network was created through the process that included many different specific planning and implementation mechanisms. Continued momentum of the programme and its success will contribute to the reorganisation of the landscape in the Ohio Lake Erie basin, which may, in turn, over time, contribute to the overall ecological and economic resilience of Lake Erie and its basin communities.

\section{Notes}

1. In England, this approach stems from the historical context of a centralised monarchy, but also from the experience of regional economic and population imbalances that resulted from nineteenth and early twentieth century industrialisation (Hall et al. 1973). In Canada, overall land use planning frameworks are set by the province and by conservation authorities operating at the regional scale. Only in recent years has control over land development been devolved to local governments in Canada, but their decisions are constrained by requirements for vertical consistency with regional and provincial plans (Chipman 2002, Wolfe 2002).

2. However, this schedule was intermpted twice because the Executive Director of OLEC was also a reservist in the US Coast Guard, and was called up on two different occasions for several months of active duty in the Great Lakes basin after the attacks in September 2001. As a result, the process was slowed down, and eventually one of the task force members, a state agency staff member, stepped in to manage the process. This person eventually was appointed as director of the OLEC staff and completed the process. However, the overall affect on the process was positive. The first director was a biologist who often appeared to struggle with the framework of regional planning 


\section{OHIO'S BALANCED GROWTH PROGRAM}

and organising the deliberation process. The second director was a trained planner with experience in several state agencies and a regional planning organisation. He was better versed in the subject matter and was experienced in running deliberative processes.

3. '1000 Friends of (state name)' organisations were popular in many states during the 1980 s and $1990 \mathrm{~s}$ in the US. Typically, these organizations, formed to advocate to state governments for land preservation and conservation, focused on natural systems or rural landscapes, but their work expanded to include broader smart growth issues in the states used as comparators.

4. The Utne Reader is a digest of independent ideas and alternative culture and forward thinking in the US about everything from the environment to the economy, politics to pop culture. For more than 20 years, Utne has functioned as a guide to the alternative and independent press. The Utne Reader's management office is located in Minneapolis, Minnesota and is a publication of Ogden Publication, Topeka, Kansas. URL: www/ utne.com.

5. This anthor served as chair of the workgroup, co-ordinating meeting agendas, meeting presentations and other aspects of the process with the task force chair and the executive director of OLEC:

6. This author co-chaired the Indicator Project with the Director of OLEC.

7. The outputs also included a set of zoning ordinances and guidelines for local government land management practices, which is beyond the scope of this paper.

\section{References}

Abbott, C., 2002. Planning a sustainable city: The promise and performance of Portland's urban growth boundary. In: G Squires, ed. Urban sprawl: casuses, conseguences and policy responses. Washington, DC: The Urban Institute Press, 207--236.

Agócs, C., 1997. Institutionalized resistance to organizational change: denial, inaction and repression. Joumal of business ethics, 16 (9), 917-931.

Ashforth, B., 1992. The perceived inequity of systems. Administration and society, 24 (3), $375-408$.

Astleithner, F. and Hamedinger, A., 2003. The analysis of sustainability indicators as socially constructed policy instruments: benefits and challenges of 'interactive research'. Local environment, 8 (6), $627-640$.

BG Task Force Minutes. November 2001.

Bengston, D., Fletcher, J., and Nelson, K., 2004. Public policies for managing urban growth and protecting open space: policy instruments and lessons learned in the United States. Landscape and urban planning, 69, 271-286.

Blair, R., 2001. Managing urban growth: can the policy tools approach improve effectiveness? Public works management and policy, 6 (2), 102-113.

Booher, D., 2004. Collaborative governance practices and democracy. National civic review, (Winter), 32-46.

Breggin, L., 2003. Planning for biodiversity: authorities in state land use laws. Washington, DC: Environmental Law Institute.

Carruthers, J., 2002. The impacts of state growth management programs: a comparative analysis. Urban studies, 39, 1959-1982.

Carruthers, J. and Ulfarsson, $G_{.}, 2002$. Fragmentation and sprawl: evidence from interregional analysis. Growth and change, 33, 312-340.

Chipman, J., 2002. A law unto itself: how the Ontario Municipal Board has developed and applied land use planning policy. Toronto: University of Toronto Press.

Clean Water Act, 1972. 33 U.S.C. $\$ 1251$ et seq.

Coastal Resources Center, 2004. Research and leaming. [online] Available from: www.cre.uri.edu/comm/research pubs.html [Accessed July 2008].

Cohen, J., 2002. Maryland's 'smart growth': using incentives to combat sprawl. $\mathrm{m}$ : G. Squires, ed. Urban sprawl: causes, consequences, and policy responses. Washington, DC: The Urban Institute Press, 293-324.

Cooper, T. and Kathi, P., 2005. Neighborhood councils and city agencies: a model of collaborative co-production. National civic review (Spring), 43-53. 


\section{OHIO'S BALANCED GROWTH PROGRAM}

Correl, M., et al., 1978. The effects of greenbelts on residential property values: some findings on the political economy of open space. Land economics, 54 (2), 207-217.

Cullingworth, J., 1993. The political culture of planning: American land use planning in comparative perspective. New York: Routledge.

Department of Economic Development, 2005. Keystone principles for growth, investment and resource conservation. Department of Community and Economic Development, Commonwealth of Pennsylvania. [online] Available from: http://www.newpa.com [Accessed 22 September 2007].

Edelbos, J. and Klijn, E., 2005. Managing stakeholder involvement in decision making: a comparative analysis of six interactive processes in the Netherlands. Journal of public administration research and theory, 16, 417-446.

EcoCity Cleveland, 2006. [online] Available from: http:www.ecocitycleveland.org [Accessed 21 September 2007].

GLC (Great Lakes Commission), 2005. Ohio land use roundtable summary. [online] Available from: http://glc.org/landuse/ohroundtable/ [Accessed 21 September 2007].

Hall, P., et al., 1973. The containment of urban England. Vohume I wirban and metropolitan growth processes. London: George Allen \& Unwin.

Harter, P., 1982. Negotiating regulations: a cure for the malaise. Georgetown law joumal, 71 (1), $1-118$.

Heikkila, T. and Gerlak, A., 2005. The formation of large-scale collaborative resource management institutions: clarifying the roles of stakeholders, science and institutions. The policy studies joumal, 33 (4), 583-612.

Heinz Center, 2004. Innovation by design: improving learning networks in coastal management. Washington, DC: H. John Heinz Center for Science, Economics and the Environment.

Innes, J.E. and Booher, D.E., 1999. Consensus building and complex adaptive systems. A framework for evaluating collaborative planning. Joumal of the American Planning Association, $65(4), 412-423$.

Kauffman, $G ., 2002$. What if ... the United States of America were based on watersheds? Water policy, 4 (1), $7-68$.

Kellogg, W., 2007. The state role in guiding land use change in the Ohio Lake Erie Basin: key policies, programs, and incentives for the Ohio Balanced Growth Program/ Final Report. Cleveland, Ohio: EcoCity Cleveland/Green City Blue Lake. [online] Available from: http:// www.greencitybluelake.org/images/land/wendy policy paper.pdf [Accessed 20 September 2007 .

Kellogg, W., et al., 2005. Training needs of coastal resources decision makers in Ohio's Lake Erie Basin. Coastal management, 33 (3), 335-351.

Koontz, T., 2006. Collaboration for sustainability? A framework for analyzing government impacts in collaborative environmental management. Sustainability: science, practice and policy, 2 (1), 15-24. [online] Available from: http://ejournal.nbii.org [Accessed 21. September 2007].

Koontz, T. and Johnson, E., 2004. One size does not fit all: matching breadth of stakeholder participation to watershed group accomplishments. Policy science, 37, 185-204.

Koontz, T. and Thomas, C.W., 2006. What dowe know and need to know about the environmental outcomes of collaborative management? Public administration review, 66, 111-121.

Lee, S. and Kellogg, W., 2009. Methodology for land wise and socioeconomic indicators for the Ohio Balanced Growth Program and a pilot test to establish baseline data. Cleveland, Ohio: The Urban Centre, Levin College of Urban Affairs.

Mandarano, L.A., 2008. Evaluating collaborative environmental planning outputs and outcomes. Joumal of planning education and research, 27 (4), 456-468.

Meck, S. and Perlman, K., 2002. Ohio planning and zoning law. Cleveland, OH: BanksBaldwin Law Publishing.

Nelson, A., 2002. How do we know smart growth when we see it? In: T. Szold and A. Carbonell, eds. Smart growth: form and consequences. Boston, MA: Lincoln Institute of Land Policy, 82-101.

Nelson, A. and Duncan, J., 1995. Growth management principles and practices. Chicago: American Planning Association.

Nelson, A. and Moore, T., 1996. Assessing growth management policy implementation: cases study of the United State's leading growth management state. Land use policy, 13(4), 241-259. 


\section{OHIO'S BALANCED GROWTH PROGRAM}

Newman, J., et al., 2004. Public participation and collaborative governance. Joumal of social policy, 33 (2), 203-223.

Ohio State Watershed Network, 2007. [online] Available from: http://ohiowatersheds.osu.edu [Accessed 20 September 2007].

OLEC (Ohio Lake Erie Commission), 2000. Lake Erie restoration and protection plan. Toledo, $\mathrm{OH}$ : Ohio Lake Erie Commission.

OLEC, 2004. Linking land use and Lake Erie: a framework for achieving balanced growth in the Ohio Lake Erie watershed. Toledo, OH: Ohio Lake Erie Commission. [online] Available from: http://www.epa.state.oh.us/oleo/bg1/framework.html [Accessed 20 September 2007].

OLEC, 2005. Ohio Lake Erie Commission. [online] Available from: http://www epa.state. oh.us/oleo/commissi.htm [Accessed 20 September 2007].

OLEC, 2006a. Watershed Balanced Growth Plans pilot projects. [online] Available from: http://www.epa.state.oh/oleo/bg 1/pilotprojects.html [Accessed 18 September 2007].

OLEC, 2006b. Lake Erie balanced growth strategy. Toledo, OH: Ohio Lake Erie Commission. [online] Available from: http://www epa.state.oh.us/oleo/bgl/strategy.html [Accessed 15 September 2007].

Ozawa, C.P., 1991. Recasting science: consensual procedures in public policy making. Boulder, CO: Westriew.

Pendall, R., 2003. Sprawl without growth: the upstate paradox. Washington DC: The Brookings Institution/Center on Urban and Metropolitan Policy.

Pendall, R., Martin, J., and Fulton, W., 2002. Holding the line: urban containment in the United States. Washington DC: The Brookings Institution/Center on Urban and Metropolitan Policy. [online] Available from: http//www brook.edn/dybdocroot/es/urban/publications/ pendallfultoncontainment.pdf [Accessed 1 June 2006].

Pfeffer, J. and Salancik, G., 2003. The external control of organizations: a resource dependence perspective. Stanford, CA: Stanford Business Books.

Planning and Incentives Workgroup, 2002. Meeting Agenda. Ohio Lake Erie Commission Balanced Growth Program, Toledo, Ohio.

Planning and Incentives Workgroup, 2003a. Meeting Agenda and Notes, 22 January 2003. Ohio Lake Erie Commission Balanced Growth Program, Toledo, Ohio.

Planning and Incentives Workgroup, 2003b. Meeting Agenda and Minutes, 23 July 2003. Ohio Lake Erie Commission Balanced Growth Program, Toledo, Ohio.

Randolph, J., 2004. Collaborative environmental management and public participation. $\mathrm{m}$ : J. Randolph, ed. Environmental land use planning and management. Washington, DC: Island Press, 53-74.

Richardson, J., Gough, M., and Pnentes, R., 2003. Is home rule the answer? Clarifying the infuence of Dillon's rule on growth management. Washington, DC: The Brookings Institution/Center on Urban and Metropolitan Policy.

Val, M. and Fuentes, C., 2003. Resistance to change: a literature review and empirical study. Management decisions, 41 (2), 148-155.

Wiig, K.M., 2002. Knowledge management in public administration. Joumal of knowledge management, 6 (3), 224-239.

Wolfe, J.M., 2002. Reinventing planning:Canada. Progress in planning, 57 (3-4), 207-235.

Wondolleck, J.M. and Yaffee, S.L., 2000. Making collaboration work. Lessons from innovation in natural resource management. Washington, DC: Island Press. 